\title{
Causation by Disconnection
}

\author{
Jonathan Schaffer
}

Philosophy of Science, Vol. 67, No. 2. (Jun., 2000), pp. 285-300.

Stable URL:

http://links.jstor.org/sici?sici=0031-8248\%28200006\%2967\%3A2\%3C285\%3ACBD\%3E2.0.CO\%3B2-Z

Philosophy of Science is currently published by The University of Chicago Press.

Your use of the JSTOR archive indicates your acceptance of JSTOR's Terms and Conditions of Use, available at

http://www.jstor.org/about/terms.html. JSTOR's Terms and Conditions of Use provides, in part, that unless you have obtained prior permission, you may not download an entire issue of a journal or multiple copies of articles, and you may use content in the JSTOR archive only for your personal, non-commercial use.

Please contact the publisher regarding any further use of this work. Publisher contact information may be obtained at http://www.jstor.org/journals/ucpress.html.

Each copy of any part of a JSTOR transmission must contain the same copyright notice that appears on the screen or printed page of such transmission.

The JSTOR Archive is a trusted digital repository providing for long-term preservation and access to leading academic journals and scholarly literature from around the world. The Archive is supported by libraries, scholarly societies, publishers, and foundations. It is an initiative of JSTOR, a not-for-profit organization with a mission to help the scholarly community take advantage of advances in technology. For more information regarding JSTOR, please contact support@ jstor.org. 


\title{
Causation by Disconnection*
}

\author{
Jonathan Schaffert: \\ Department of Philosophy, University of Houston
}

The physical and/or intrinsic connection approach to causation has become prominent in the recent literature, with Salmon, Dowe, Menzies, and Armstrong among its leading proponents. I show that there is a type of causation, causation by disconnection, with no physical or intrinsic connection between cause and effect. Only Hume-style conditions approaches and hybrid conditions-connections approaches appear to be able to handle causation by disconnection. Some Hume-style, extrinsic, absence-relating, necessary and/or sufficient condition component of the causal relation proves to be needed.

1. Introduction. It is widely believed that causation requires a connection from cause to effect, such as an energy flow. But there are many ways to wire a causal mechanism. One way is to have the cause connect to the effect, but another is to have the cause disconnect what was blocking the effect.

The detonator button is pressed and the bomb explodes. Surely this is causation (this is not a trick case: no backup detonators or anything like that). If you do not already consider the causation here obvious, I offer the following intuition-buttressing considerations. Counterfactually, had the button not been pressed then the bomb would not have exploded. Statistically, bomb explosions will universally follow button pressings in such circumstances. The explanation for why the bomb exploded will surely include the button pressing. Knowing of the pressing will license a prediction of the explosion, and knowing of the explosion will license a retrodiction to the pressing. Button pressings in such circumstances constitute an effective strategy for explosion-hungry agents. The button

*Received November 1999; revised February 2000.

$\dagger$ Send requests for reprints to the author, Department of Philosophy, University of Massachusetts, Bartlett Hall, Amherst, MA 01003.

$\Varangle$ Thanks to Phil Dowe, Jim Hawthorne, and David Lewis, and especially to Ned Hall for bringing my attention to this type of case.

Philosophy of Science, 67 (June 2000) pp. 285-300. 0031-8248/2000/6702-0011 $\$ 2.00$

Copyright 2000 by the Philosophy of Science Association. All rights reserved. 
presser will be held morally responsible for the consequences of the explosion. Here all the central connotations of causation are in full force.

But I have not said how the detonator is wired. Perhaps pressing the button generates an electrical current which connects to the bomb and makes it explode: ${ }^{1}$

Button not pressed pressing $O \longrightarrow 0$ explosion
Button pressed pressing $\longrightarrow$ explosion

Or perhaps pressing the button disconnects an electrical current that was inhibiting an independent source from triggering the explosion:
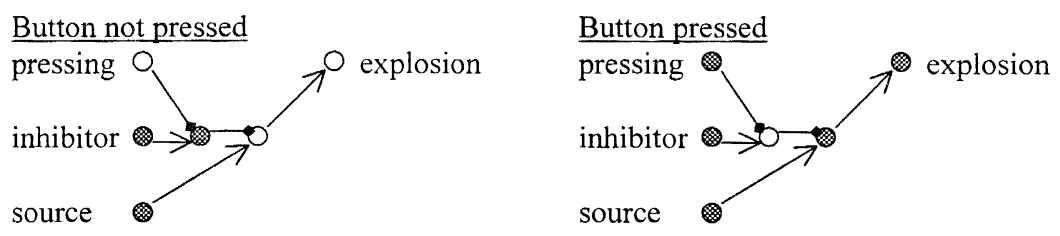

Either way is causation full force. ${ }^{2}$

See the pattern and you'll find it everywhere, even in the most paradigmatic causal sequences. The killer gets angry (C), pulls the trigger (D1), fires a bullet through the victim's heart (D2), and the victim dies (E). Here is a paradigm of causation, with causation by disconnection at every step.

Working backwards, surely the firing of the bullet through the victim's heart (D2) is a cause of his death (E). But heart piercings cause death only by disconnection. The brain is kept alive by an influx of oxygenated blood, and heart piercings cause death by disconnecting this influx, allowing oxygen starvation to run its course:

1. Diagram conventions: filled circles doubly represent neurons that fire and events that occur, unfilled circles doubly represent neurons that do not fire and events that do not occur, arrows represent stimulatory connections, and lines ending in squares represent inhibitory connections. If two neurons are connected by a stimulatory connection and the first fires, then the second will fire unless inhibited.

2. Terminological note: Since the pressing prevents the inhibitor from preventing the source, disconnections may also be called (following Ned Hall) "double preventions." But beware: I use "prevention" (following Phil Dowe) to denote a relation that occurs but once when the button is pressed, viz.,

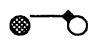




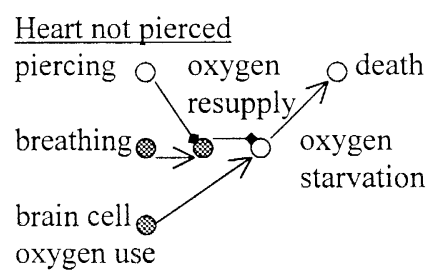

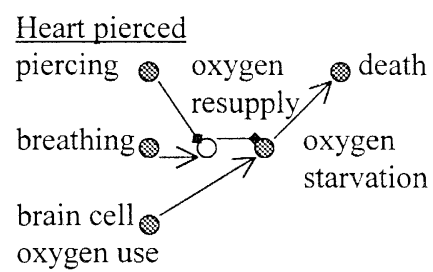

The Center for Disease Control (which is fully aware of the wiring) identifies heart disease as "the leading cause of death" in the United States.

At the next step backward, surely the killer's pulling the trigger (D1) is a cause of the firing of the bullet through the victim's heart (D2). But trigger pullings only cause bullet firings by disconnection. The spring is kept coiled by the sear, and trigger pullings cause bullet firings by disconnecting the sear, allowing the spring to uncoil (propelling the striker onto the powder, compression of which produces the explosion which propels the bullet):

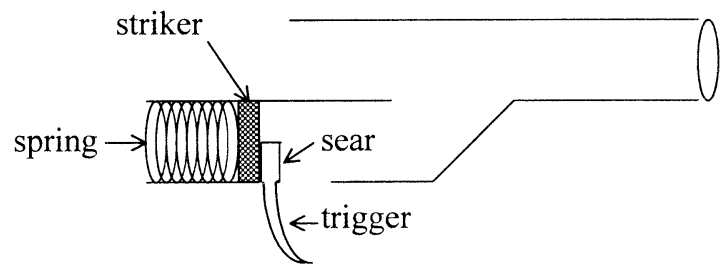

Diagrammatically:
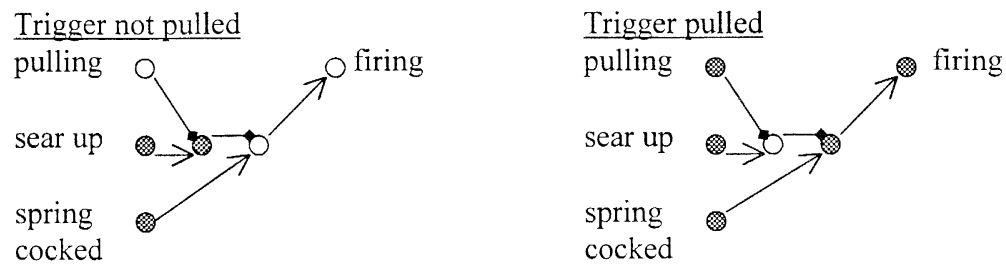

Even the National Rifle Association, which insists that "guns don't kill people, people kill people" to blame the shooter rather than the weapon, concedes thereby that shooters of guns can cause death.

Finally back to the first step, surely the killer's getting angry $(\mathrm{C})$ is a cause of his pulling the trigger (D1). But nerve signals only cause muscle contractions (such as that of the trigger finger) by disconnection. Muscle 
fibers, according to the generally accepted sliding filament theory, contract by myosin-actin binding, which is blocked by the presence of tropomyosin on the binding sites of the actin. Contraction occurs when the electrical impulse from the nerve triggers a calcium cascade through the fiber. The calcium binds to troponin (attached to each tropomyosin molecule) and the troponin-calcium complex disconnects the tropomyosin from the binding sites:

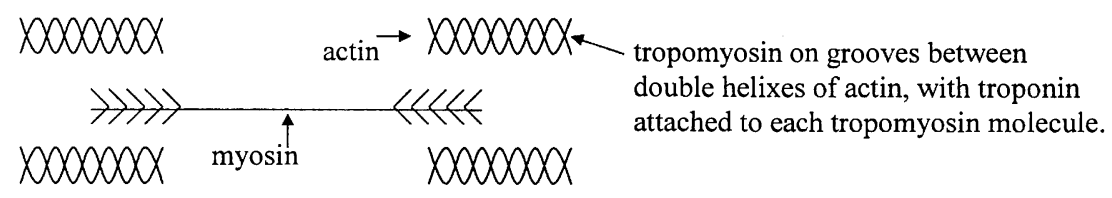

(Myosin proteins work like coiled springs, set to grab the actin when released). Diagrammatically:

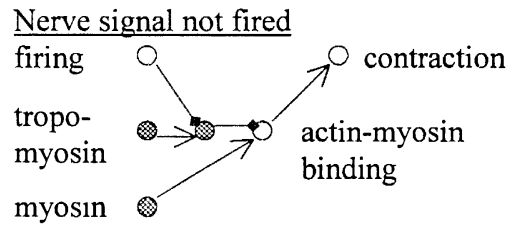

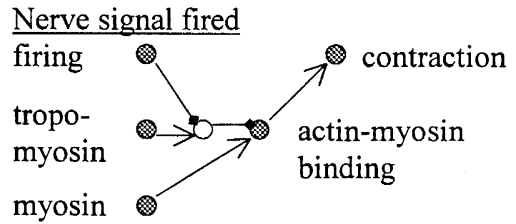

Philosophers such as R. C. Collingwood (1940), Douglas Gasking (1955), G. H. von Wright (1975), and Huw Price (1991) have alleged that causation is an anthropomorphic concept, inextricably entangled with the idea of human agency. While I would maintain that an objective concept of causation can be isolated, surely this concept must still apply to voluntary human actions, which are due to muscle contractions.

See that disconnections are both ubiquitous and paradigmatically causal and you'll find them in even the most theoretically salient instances of causation. When Saul Kripke (1972) speaks of the reference of names as transmitted via causal chains, it should be obvious that his claim does not turn on just how the printing press is wired. When Brian Skyrms (1980) speaks of rational decisions as those that maximize the expected utility of their effects, it should be obvious that this calculation is indifferent as to whether the effects are achieved by connection or disconnection. When Alvin Goldman speaks of perception as a causal relation (1977), he explicitly notes that one can perceive black holes without any energy coming from them (rather the black hole disconnects light that would otherwise be visible), and Michael Tye notes that: "This difficulty is not peculiar to 
astronomical contexts. It seems to me that perfectly black objects which are not too small or too distant may be seen with the naked eye provided that they are located against light backgrounds" $(1982,324)$.

Causation by disconnection is causation full force, involving all the central connotations of causation such as counterfactuals, statistics, explanation, inference, agency, and responsibility, involved in even the most paradigmatic cases of causation including all instances of human action, and involved in the most theoretically salient cases of causation relevant to the analyses of reference, decision, and perception. I cannot see a stronger argument that anything is causal. ${ }^{3}$

Causation by disconnection is different than causation by connection (and liable to be overlooked if one concentrates on colliding billiard balls) but no less causal thereby. There is more than one way to wire a causal mechanism.

2. Physical Connections. David Hume glossed our naive conception of causation as that of necessary connection. While Hume thought the connection not in the objects but projected by the mind, a number of subsequent philosophers have addressed the Humean problematic by seeking a connection in the objects via physical processes such as energy flows.

Causation by disconnection refutes this program. The causal connection of which Hume speaks may well be objective, but is more abstract than simple physical connection.

There are three intimately related research programs running today that take physical connection to be at least necessary (if not sufficient as well) for causation. I will be extremely brief here, since causation by disconnection refutes not the details of these various programs, but their underlying thought.

First, there is the program of Jerrold Aronson, David Fair, and HectorNeri Castaneda, on which property transfer, or more specifically energy transfer, is taken to be at least necessary for causation. For Aronson, causation is transference of a quantity (velocity, momentum, kinetic energy, and heat are given as examples, though no definite class of relevant quantities is specified) by intervening contact action of cause into effect, so that, " ' $A$ ' in 'A causes B' refers to an object that successfully transfers one of its quantities to the effect object." (1971, 422). For Fair, "A causes $\mathrm{B}$ iff there are physical redescriptions of $\mathrm{A}$ and $\mathrm{B}$ as some manifestation

3. Cases of disconnection have floated through the literature for some time now, although their full force has perhaps yet to be appreciated. For example, Douglas Ehring $(1986,251)$ speaks of causation by elimination of transfer in the case of turning off a light switch; but then Ehring (1997) requires physical connection between cause and effect, with no mention of disconnections. 
of energy or momentum or refer to objects manifesting these that is transferred (flows), at least in part, from the A-objects to the B-objects" (1979, 236). ${ }^{4}$ And for Castaneda (1984) causation requires both transfer (of "causity', empirically identified with energy) and Humean constant contiguous conjunction.

A second physical connection program is that of Bertrand Russell, Wesley Salmon, and Phil Dowe, on which processes are taken to be basic entities, the causal ones of which must be specified. For Russell (1948) the specification is in terms of spatiotemporally continuous qualitative persistencies. For Salmon (who notes that Russell's specification applies to joint effects of a common cause such as a moving spot of light projected from a rotating beacon) mark transmittability is added, where, "A mark is an alteration to a characteristic that occurs in a single local intersection" and "A mark is transmitted over an interval when it appears at each spacetime point of that interval, in the absence of interactions" $(1998,250)$. Thus a causal process, for Salmon, is a spatiotemporally continuous persistence that is capable of transmitting a mark, of propagating structure. And for Dowe $(1992,1995)$ a causal process is the worldline of an enduring conserved-quantity-bearing object. ${ }^{5}$

A third physical connection program is that of J. L. Mackie and Douglas Ehring, on which a causal mechanism is postulated as: "a process which underlies a regular sequence and each phase in which exhibits qualitative as well as spatio-temporal continuity" (Mackie 1974, 222). Mackie finds in this notion certain senses in which causes necessitate their effects, especially that of the 'intimate tie' between cause and effect. Ehring (1997) develops this thought by specifying the relevant qualitative continuity as trope identity-through-time, and the intimate tie found therein as intrinsic relation.

All three research programs are deeply interrelated, and owe their distinctive flavors as much to historical pedigree as to philosophical difference. All understand physical connections as persistencies, and differ only in what is said to persist: unspecified for Russell and Mackie, properties for Aronson and tropes for Ehring, energy for Fair and Castaneda, structure for Salmon, and objects instantiating conserved quantities for Dowe.

It is obvious that these property transfer/causal process/underlying mechanism programs have no room for causation by disconnection, since

4. According to Wladyslaw Krajewski (1997), energy flow accounts of causation trace back to Robert Mayer (the discoverer of the law of conservation of energy) in 1842, and have been advocated by such scientific luminaries as Helmholtz, Planck, and Lorentz.

5. Salmon $(1994,1998)$ now embraces Dowe's shift from capacities to conserved quantities, and now speaks of causal processes as those that transmit conserved quantities. 
causation by disconnection involves no persistence line between disconnector and effect, but rather the severing of one, as the wiring diagram makes manifest:

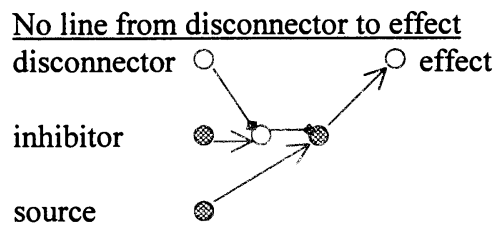

Thus for Aronson, Fair, and Castaneda there will be no property transferred from, e.g., the nonbeating heart to the oxygen-starving brain, for Russell, Salmon, and Dowe there will be no causal process between them, and for Mackie and Ehring there will be no persistence mechanism tying these events together. Not all ways of wiring a causal mechanism involve persistence.

Those connection theorists alive to the problem of disconnection have hitherto bitten the bullet. Here is Aronson:

Consider a weight that is attached to a stretched spring. At a certain time, the catch that holds the spring taut is released, and the weight begins immediately to accelerate. One might be tempted to say that the release of the catch was the cause of the weight's acceleration. If so, then what did the release of the catch transfer to the weight? Nothing, of course $(1971,425)$.

Such a dismissal might be tolerable were it limited to the isolated case of launching a weight by a spring, but once it is seen that spring-release-like mechanisms are ubiquitous in nature, present throughout the most intuitively paradigmatic as well as the most theoretically salient causal sequences, with all the conceptual connotations of causation in full force, such a dismissal becomes absurd. No theory so dismissive is close to deserving the name "causation."

3. Intrinsic Relations. Hume's empiricist reconception of causation is that of regularity of sequence in the objects together with felt necessity in the mind: constant contiguous conjunction with conditioned conceptual connection. Hume notes, as a counterintuitive consequence of his reconception, that it is "drawn from circumstances foreign to the cause" (1975, 362 ), and some subsequent philosophers have rejected the Humean reconception by seeking a notion of causation not "drawn from circumstances foreign" but rather drawn from intrinsic relations. 
According to Peter Menzies, causation is a theoretical notion, functionally defined as the intrinsic relation that typically induces probabilistic counterfactual dependence between actual, distinct events. A relation is intrinsic in the intended sense (intrinsic to its pairs) iff whenever $\langle a, b\rangle$ and $\left\langle a^{\prime}, b^{\prime}\right\rangle$ are duplicate pairs, either both or neither of the pairs stand in the relation, where $\langle a, b\rangle$ and $\left\langle a^{\prime}, b^{\prime}\right\rangle$ are duplicate pairs iff $a$ and $a^{\prime}$ have the same natural properties, so do $b$ and $b^{\prime}$, and the natural relations between $a$ and $b$ are the same as between $a^{\prime}$ and $b^{\prime}$. Menzies asserts that:

The distinctive mark of our intuitive conception of causation ... is that it takes causal relations to be determined by the natural properties of the relata and the natural relations holding between them, taken in isolation from everything else happening in the world. $(1996,100)$

According to David Armstrong, causation is a primitive notion, empirically identified with the instantiation of the second-order necessitation universal $\mathrm{N}$ (Armstrong's lawmaker) between states of affairs: $\mathrm{Fa}$ and $\mathrm{Gb}$ are causally related in virtue of an instantiation of $\mathrm{N}(\mathrm{F}, \mathrm{G})$. Armstrong notes with satisfaction that, "[E]ach instantiation of a universal is complete in itself, so the law will be present completely in each instantiation. So where singular causation is the instantiation of such a law it will be a completely intrinsic relation" $(1999,184){ }^{6}$

The idea of causation as an intrinsic relation may be regarded as a generalization of the idea of causation as a physical connection. As Menzies puts it, "[T]here is an intrinsic relation connecting the event of my throwing the stone and the window's breaking, a process consisting in the transfer of energy-momentum from cause to effect." $(1996,105)$ For Armstrong energy flows could be regarded as a this-worldly instance of lawful sequence. And for Ehring requiring the physical connection of trope persistence is a way to ensure intrinsicness.?

It is obvious that intrinsic relation programs, like physical connections, have no room for causation by disconnection, since causation by disconnection turns on the extrinsic circumstance of a preexisting connection to be severed. For example, the nerve signal and fiber contraction are causally

6. For Armstrong, the states of affairs related by causation contain first-order universals (the $\mathrm{F}$ of $\mathrm{Fa}$ ). I will argue in the next section that causation by disconnection requires absence causation. Since Armstrong rejects negative first-order universals, mediation by absences represents an additional conflict (other than extrinsicness) between what Armstrong calls 'causation' and any relation that covers disconnections.

7. According to Alexander Rueger, neither energy-momentum flow nor conserved quantity transmission are in fact intrinsic as scientifically defined, since both depend on global spacetime structure. Rueger concludes that "the localist intuition, though presumably part of the 'folk theory of causation', is just not correct and has to be given up" $(1998,37)$. 
related only due to the extrinsic circumstances of tropomyosin being present, since a perfect duplicate of the signal and the contraction could exist without any causal relation if the fibers in question were missing the tropomyosin that the nerve signal is normally needed to disconnect. In that case there would be nothing for the signal to accomplish:

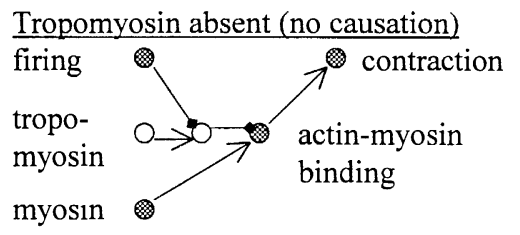

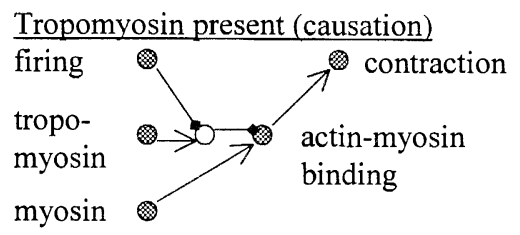

Here the 'foreign circumstance' of the presence or absence of the inhibitor changes whether $\mathrm{C}$ and $\mathrm{E}$ are causally related. Not all ways of wiring a causal mechanism involve intrinsic relations.

I admit that there is something intuitive about intrinsicness, but deny that this intuition can withstand philosophical scrutiny. Intrinsicness seems an isolated intuition, with no clear relation to the other central connotations of causation (such as counterfactuals, regularities, explanation, inference, responsibility, and agency). Causation by disconnection pulls these apart. It reveals that we must choose between, on the one hand, a conception of causation that is tied into the holding of the central connotations of causation, that applies to such paradigmatic causes as heart attacks, gun firings, and human actions, and that supports a causal analysis of reference, decision, and perception, inter alia, versus, on the other hand, a conception of causation that is intrinsic. Thus I think intrinsicness, like the principle of determinism, the law of universal causation, and the homology of cause to effect, belongs among the platitudes which a systematic conception of causation should reject.

A limited intrinsicness thesis may still hold for a component of the causal relation. I think causation is best understood in terms of a hybrid conditionconnection account ( $\mathrm{C}$ causes $\mathrm{E}$ iff an actual E-connection depends on $\mathrm{C}$; see §5). I think the connection component is best understood (Armstrongstyle) in terms of sequences of events subsumed under antecedent and consequent of the fundamental dynamic laws. ${ }^{8}$ Now, holding the laws fixed (which may themselves be extrinsically determined by the systematic regularities), the connection component of causation is intrinsic to the extent that the laws project intrinsic properties. Perhaps this more modest 
sense of the intrinsicness-given-our-laws of the connection component of causation is all the folk ever had in mind.

4. Conditions and Absences. What constraints are imposed on a theory of causation adequate to understand how the many ways of wiring a causal mechanism are all instances of causation?' ${ }^{9}$ I suggest that the constraints imposed by disconnections are that an adequate theory of causation must involve necessary and/or sufficient conditions, and must relate absences.

The main alternative to physical/intrinsic connection approaches to causation is the Hume-style, generalist, abstract, extrinsic, necessary and/ or sufficient conditions approach. Conditions approaches (such as Hume's regularity and David Lewis's counterfactual dependence approaches) have no difficulty with disconnections. In whatever sense causes are supposed to be necessary and/or sufficient for their effects, the disconnector will be necessary and/or sufficient for what it releases. For example, the death will counterfactually depend on the heart piercing. ${ }^{10}$

But what of the spatiotemporal continuity of causation? Perhaps spatiotemporal continuity is not metaphysically necessary. Perhaps it is not even physically necessary in the quantum domain. But surely it holds in cases of heart failure, gun firings, and muscle contractions: no magical or quantum connections are at issue. What are the intermediaries between, e.g., heart piercing and brain death?

Answer: the relevant intermediaries are absences: the heart piercing causes an absence of oxygenated blood traveling from the right ventricle, through the relevant arteries, to the brain, which absence causes an absence of oxygen resupply to the brain cells, which absence causes oxygen starvation. That is to say that the continuous sequence is:

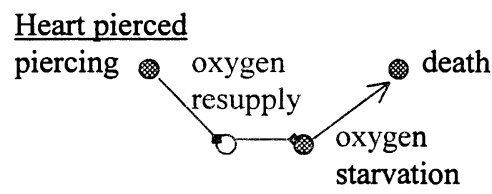

9. I assume (a) that the ways of wiring a causal mechanism have something substantive in common in virtue of which both are causations, and (b) that something informative can be said about this commonality. Thus I assume in what remains that causation is a univocal nonprimitive.

10. Probabilistic and agential approaches also count as conditions approaches. All these approaches, once extended to the indeterministic case, converge on understanding causation as some form of probability-raising relation. In general, the disconnector will raise the probability of what it releases. 
where the second link is a line of absences. Pure conditions approaches need absences to recognize the spatiotemporal continuity of disconnective causation.

Some philosophers find absence causation unproblematic while others find it abhorrent. I think this clash of intuitions is a manifestation of the clash between conditions and connections conceptions of causation: absences are perfectly suitable as conditions but not as connectors. Thus Lewis (a conditions theorist) takes it as intuitively obvious that when Fred omits the precautions he causes the accident (1986, 189-193), while Armstrong (a connections theorist) intuits: "[O]missions and so forth are not part of the real driving force in nature. Every causal situation develops as it does as a result of the presence of positive factors alone" $(1999,177)$.

So far this clash seems stalemated. Intuitively we want to say that the gardener's failure to water the flowers (absence) caused them to die, ${ }^{11}$ but to deny that your, my, or the queen of England's failure to water the flowers caused them to die. Those like Lewis who speak of absences as causal may point to the holding of the central connotations of causation between the gardener's failure and the flowers' death, while those like Armstrong who deny that absences are causal may point to the proliferation of counterintuitive causes thereby countenanced. ${ }^{12}$

I think the defender of absences as causal already has the better of it. A pragmatic explanation of why it is infelicitous to speak of the queen's failure as a cause is readily available: since I never presumed that the queen would deign to water my flowers, to speak of this absence is to impart no information not already supposed. And since both the conditions and connections theorists must (counterintuitively) count my birth as a cause of my coughing now, both sides are already committed to the pragmatic machinery involved.

In any case, since disconnections show that absences mediate the causation in such paradigmatic cases as heart attacks, gun shots, and human actions, and can mediate the causation in such theoretically salient cases as are relevant to the analysis of reference, decision, and perception, these considerations should definitely settle the issue over absences. Thus conditions approaches which relate absences (as was already thematic for the

11. See Hart and Honore 1959 for numerous examples of causation by omission recognized in the law, such as "failure to deliver to a manufacturer on time a piece of machinery, which he has ordered, may be held the cause of the loss of those profits which would have been made by its use" $(1959,56)$.

12. The most intuitive theory would count the gardener's failure but not the queen's as a cause. But it is doubtful that there is any ontological basis for such a discrimination. It would seem that, for any theory of causation with aspirations to objectivity, the only options with respect to absences are all or none. 
conditions theorist) provide a unified and informative account of what the many of ways of wiring a causal mechanism have in common.

5. Hybrid Approaches. Other than the necessary and/or sufficient conditions approach, the only other approach to causation I know of which is adequate to disconnections is a hybrid conditions-connections approach (which explicitly involves conditions and relates absences). It will emerge, however, that major revision of the extant hybrids is required.

Fair concludes on intuitive grounds that absences are causal, and recognizes that his energy flow account cannot accommodate them, since absences "cannot be the sources or sinks of actual energy-momentum" $(1979,246)$. He responds by suggesting a hybrid counterfactual-energy approach:

(1) Connective causation: $\mathrm{C}$ causes $\mathrm{E}$ iff (a) $\mathrm{C}$ and $\mathrm{E}$ are actual, distinct events and (b) $\mathrm{C}$ is physically (/intrinsically) connected to $\mathrm{E}$.

(2) Causation by prevention: $\mathrm{C}$ causes $\sim \mathrm{E}$ iff (a) $\mathrm{C}$ occurs and $\mathrm{E}$ does not, and (b) $\mathrm{C}$ is a connective cause (by 1 ) of an $\mathrm{E}^{\prime}$ incompatible with E.

(3) Causation by omission: $\sim \mathrm{C}$ causes $\mathrm{E}$ iff (a) $\mathrm{C}$ does not occur and $\mathrm{E}$ does, and (b) had C occurred, it would have connectively caused (by 1) an $\mathrm{E}^{\prime}$ incompatible with $\mathrm{E}$.

(4) Causation by omission of prevention: $\sim \mathrm{C}$ causes $\sim \mathrm{E}$ iff (a) neither $\mathrm{C}$ nor $\mathrm{E}$ occurs, and (b) had $\mathrm{C}$ occurred, it would have connectively caused (by 1) E. ${ }^{13}$

It might seem that the hybrid theorist can trace the conditions theorist's approach to spatiotemporal continuity and maintain, for example, that heart piercing $(C)$ causes an absence of oxygen resupply to the brain cells $(\sim \mathrm{D})$ by $(2)$, that the absence of oxygen resupply to the brain cells $(\sim \mathrm{D})$ causes brain death (E) by (3), so that heart piercing (C) causes brain death (E). But the hybrid approach does not chain. Heart piercing causing brain death is of form (1), and the hybrid approach equates causation of form (1) with connection.

Solution: understand conditions (1)-(4) as defining direct causation, and understand causation generally in terms of chains of direct causations. ${ }^{14}$

13. Dowe (1999) refines Fair's hybrid approach, analyzing preventions and omissions via counterfactuals about connection. Yet Dowe insists on a pure (actual) connections approach to causation, and so relegates his refinement to ersatz status. I think this is a highly unstable position. Disconnections show that what Dowe dismisses as ersatz causation* is far more deserving of the title "causation" than the pure connections approach.

14. Fair clearly intends the hybrid relations to be closed under transitivity $(1979,248)$. Chaining can also be accomplished by requiring the spatiotemporally continuous holding of the hybrid relations between $\mathrm{C}$ and $\mathrm{E}$, rather than the mere transitive closure thereof. Either works here. 
Thus disconnections can be understood to be prevention-omission chains.

But chaining infinitely exacerbates the hybrid theorist's disunity problem. Fair has already split causation into four relations, and now with chaining when $\mathrm{C}$ is said to cause $\mathrm{E}$ all that is so far specified is some arbitrarily complex combination of direct causations. We have not really understood why (1)-(4) are all causations in the first place, and so are in no position at all to maintain that all $n$-length chains thereof (e.g., (1)-(2)(4)-(3)-(2)- . . , (4)-(3)-(2)-(4)- . . , etc.) are all causations. ${ }^{15}$

Solution: the hybrid theorist, to regain unity, must (a) unify absences and presences into a single form, and then (b) generalize to a common hybrid relation across the now formally unified (1)-(4). Thus chaining would entail simple repetition rather than arbitrary complexity. (If neither this nor any other hybrid-unifying strategy can be implemented, then disconnections will have the upshot that only a pure conditions approach is adequate.)

In order to unify absences and presences into a single form as per (a), the hybrid theorist looks to have three main approaches. The first is to take the causal relata as abstract facts, since that there is oxygen resupply to the brain and that there is no oxygen resupply to the brain are equally of factive form. But it is hard to see how there could be any connection to such an abstraction. The second is to take the causal relata as concrete unstructured events and interpret the event described as "an absence of oxygen resupply" to refer to a present proxy that stands in the incompatibility relation to this absence. But it is hard to see how the conditions could hold for such a proxy, since, for instance, the proxy has the wrong counterfactual behavior: if the proxy for the fridge holding no beer is its being full of sausages, then it does not follow that had the fridge not been full of sausages then it would have held beer. ${ }^{16}$ The third main approach, which seems best, is to take the causal relata as concrete structured events on which the causal relata are ordered 〈Property, Region〉 pairs with negative properties allowed so as to include absences. ${ }^{17}$ These pairs have the right counterfactual behavior, since the supposition that the $\langle$ absence of

15. Lewis (1998) suggests understanding the hybrid relations as direct causation, raises the disunity objection, and concludes that while the hybrid approach might well specify a supervenience base for causal relations, it is far too disjointed to be regarded as an analysis of the causal concept.

16. Perhaps this is salvageable, since it is generally recognized that there is at least some context-dependence in the assessment of the counterfactual value of $\sim \mathrm{C}$ (Lewis 1986, 6 . Thus it might be maintained that referring to the proxy via the absence-description creates a context in which the supposition that the proxy does not occur is best interpreted as the supposition that the absence in the description is present.

17. This approach is inspired both by Jaegwon Kim's understanding of the causal relata as $\langle$ Object, Property, Time $\rangle$ triples, as well as by D. C. Williams's understanding of the causal relata as tropes. 
beer, fridge region $\rangle$ event does not occur is the supposition of a beerful fridge. Call the disjunction of a positive relata or a positive proxy for a negative relata the manifestation of the relata in question. Then the relevant connection for these pairs is the connection to the manifestation of the effect.

Here then is a suggestion as per (b) for framing a unified hybrid relation for the $\langle$ Property, Region〉 pairs that formally unify absent and present relata:

$\mathrm{C}$ directly causes $\mathrm{E}$ iff (a) $\mathrm{C}$ and $\mathrm{E}$ are actual, distinct events, and (b) had $\mathrm{C}$ not occurred, then an (actual) connection to the E-manifestation would not have occurred.

In short, the thought is that an (actual) E-connection depends on C. Connective causation $(\mathrm{C} / \mathrm{E})$, previously understood in terms of $\mathrm{C}$ being connected to $\mathrm{E}$, is now understood in terms of connection dependence. In other words, if $\mathrm{E}$ would have occurred at all without $\mathrm{C}$ it would have been via a nonactual connection (such as via a preempted backup). Causation by prevention $(\mathrm{C} / \sim \mathrm{E})$, previously understood in terms of $\mathrm{C}$ being a connective cause of an $\mathrm{E}^{\prime}$ incompatible with $\mathrm{E}$, is likewise understood on the counterfactual: had $\mathrm{C}$ not occurred, then if $\mathrm{E}^{\prime}$ (the E-manifestation) would have occurred at all it would have been via a different connection. The reader may compare the understandings of causation by omission $(\sim \mathrm{C} / \mathrm{E})$ and by omission of prevention $(\sim \mathrm{C} / \sim \mathrm{E}) .{ }^{18}$

One consequence of this unification is that disconnections can again be understood directly (just as with the conditions approach), since, e.g., the connection to brain death depends directly on the heart piercing. So we can kick away the ladder of direct causation and reach:

$\mathrm{C}$ causes $\mathrm{E}$ iff (a) $\mathrm{C}$ and $\mathrm{E}$ are actual, distinct events, and (b) an E-process depends on C. (Where an E-process is an actual connection to an E-manifestation.)

Both the conditions and (suitably refined) hybrid conditions-connections approaches seem equally adequate to causation by disconnection. I believe, however, that when we turn to problem cases such as preemption the hybrid approach will perform significantly better. Moreover, the hybrid approach can explain what is right in the connections approach: causation does turn out to be based in actual connections, just not directly.

18. There are differences between the disunified relations reported above and their unified generalization developed here. In the $\mathrm{C} / \mathrm{E}$ case for instance, the unified generalization entails that if $\mathrm{C}$ is an inessential part of the connection (a speck of dust on the bullet), then $\mathrm{C}$ is not a cause of $\mathrm{E}$, since that connection would, in essence, still occur without $\mathrm{C}$, while the disunified relations must count such an inessential $\mathrm{C}$ as a connective cause of E. Further confirmation for the unified generalization. 
Rather we must take a further step of abstraction and speak of conditions for connections. I leave a full comparison of these approaches to another day. ${ }^{19}$

I know of no other approach to causation able to explain how the many ways of wiring a causal mechanism are all instances of causation. Since both the conditions and hybrid approaches involve conditions and relate absences, I conclude that causation by disconnection yields a powerful argument for the involvement of Hume-style, extrinsic, absence-relating, necessary and/or sufficient conditions in any adequate theory of causation.

\section{REFERENCES}

Armstrong, David (1999), "The Open Door: Counterfactual versus Singularist Theories of Causation", in Howard Sankey (ed.), Causation and Laws of Nature. Dordrecht: Kluwer, $175-186$.

Aronson, Jerrold (1971), "On the Grammar of Cause”, Synthese 22: 414-430.

Castaneda, Hector-Neri (1984), "Causes, Causity, and Energy", in Peter French, Theodore Uehling Jr., and Howard Wettstein (eds.), Midwest Studies in Philosophy Volume IX: Causation and Causal Theories. Minneapolis: University of Minnesota Press, 17-28.

Collingwood, R. G. (1940), An Essay on Metaphysics. Oxford: Clarendon Press.

Dowe, Phil (1992), "Wesley Salmon's Process Theory of Causality and the Conserved Quantity Theory", Philosophy of Science 59: 195-216.

- (1995), "Causality and Conserved Quantities: A Reply to Salmon", Philosophy of Science 62: 321-333.

- (1999), "Good Connections: Causation and Causal Processes", in Howard Sankey (ed.), Causation and Laws of Nature. Dordrecht: Kluwer, 247-264.

Ehring, Douglas (1986), “The Transference Theory of Causation", Synthese 67: 249-258.

- (1997), Causation and Persistence. New York: Oxford University Press.

Fair, David (1979), "Causation and the Flow of Energy", Erkenntnis 14: 219-250.

Gasking, Douglas (1955), "Causation and Recipes”, Mind 64: 479-486.

Goldman, Alvin (1977), "Perceptual Objects", Synthese 35: 257-284.

Hall, Ned (2000), "Two Concepts of Causation", Journal of Philosophy (forthcoming).

Hart, H. L. A. and A. M. Honore (1959), Causation in the Law. Oxford: Clarendon Press.

Hume, David (1975), An Enquiry Concerning Human Understanding, edited by L. A. SelbyBigge and P. H. Nidditch. Oxford: Clarendon Press.

Kim, Jaegwon (1993), "Events as Property Exemplifications", in Supervenience and Mind: Selected Philosophical Essays. Cambridge: Cambridge University Press, 33-52.

Krajewski, Wladyslaw (1997), "Energetic, Informational, and Triggering Causes", Erkenntnis 47: 193-202.

Kripke, Saul (1972), Naming and Necessity. Cambridge, MA: Harvard University Press.

Lewis, David (1986), “Causation”, in Philosophical Papers, vol. 2. New York: Oxford University Press: 159-213.

(1998), "Void and Object", preprinted by the Department of Philosophy, University of Melbourne.

Mackie, J. L. (1974), The Cement of the Universe: A Study of Causation. Oxford: Clarendon Press.

Menzies, Peter (1996), "Probabilistic Causation and the Pre-emption Problem", Mind 105: 85-117.

19. See my "Causes as Probability-Raisers of Processes" (unpublished) for arguments favoring the hybrid conditions-connections approach developed here over the conditions approach. 
Price, Huw (1991), "Agency and Probabilistic Causality", British Journal for the Philosophy of Science 42: 157-176.

Rueger, Alexander (1998), "Local Theories of Causation and the A Posteriori Identification of the Causal Relation", Erkenntnis 48: 25-38.

Russell, Bertrand (1948), Human Knowledge: Its Scope and Limits. New York: Simon and Schuster.

Salmon, Wesley (1994), "Causality without Counterfactuals", Philosophy of Science 61: 297-312.

- (1997), "Causality and Explanation: A Reply to Two Critiques", Philosophy of Science 64: 461-477.

. (1998), Causality and Explanation. New York: Oxford University Press.

Schaffer, Jonathan (unpublished), "Causes as Probability-Raisers of Processes". -. (unpublished b), "Processes as Lawful Sequences".

Skyrms, Brian (1980), Causal Necessity. New Haven: Yale University Press.

Tye, Michael (1982), "A Causal Analysis of Seeing", Philosophy and Phenomenological Research 42: 311-325.

Von Wright, G. H. (1975), Causality and Determinism. New York: Columbia University Press.

Williams, D. C. (1953), "On the Elements of Being", Review of Metaphysics 7: 3-18. 
http://www.jstor.org

\title{
LINKED CITATIONS
}

\author{
- Page 1 of 2 -
}

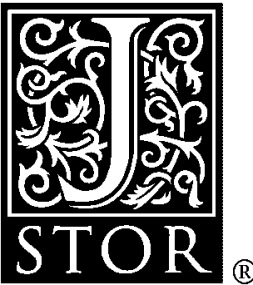

You have printed the following article:

\section{Causation by Disconnection}

Jonathan Schaffer

Philosophy of Science, Vol. 67, No. 2. (Jun., 2000), pp. 285-300.

Stable URL:

http://links.jstor.org/sici?sici=0031-8248\%28200006\%2967\%3A2\%3C285\%3ACBD\%3E2.0.CO\%3B2-Z

This article references the following linked citations. If you are trying to access articles from an off-campus location, you may be required to first logon via your library web site to access JSTOR. Please visit your library's website or contact a librarian to learn about options for remote access to JSTOR.

\section{[Footnotes]}

\author{
${ }^{5}$ Causality without Counterfactuals \\ Wesley C. Salmon \\ Philosophy of Science, Vol. 61, No. 2. (Jun., 1994), pp. 297-312. \\ Stable URL: \\ http://links.jstor.org/sici?sici=0031-8248\%28199406\%2961\%3A2\%3C297\%3ACWC\%3E2.0.CO\%3B2-S
}

\section{References}

\author{
Wesley Salmon's Process Theory of Causality and the Conserved Quantity Theory \\ Phil Dowe \\ Philosophy of Science, Vol. 59, No. 2. (Jun., 1992), pp. 195-216. \\ Stable URL: \\ http://links.jstor.org/sici?sici=0031-8248\%28199206\%2959\%3A2\%3C195\%3AWSPTOC\%3E2.0.CO\%3B2-D
}

\section{Causality and Conserved Quantities: A Reply to Salmon}

Phil Dowe

Philosophy of Science, Vol. 62, No. 2. (Jun., 1995), pp. 321-333.

Stable URL:

http://links.jstor.org/sici?sici=0031-8248\%28199506\%2962\%3A2\%3C321\%3ACACQAR\%3E2.0.CO\%3B2-M

NOTE: The reference numbering from the original has been maintained in this citation list. 
http://www.jstor.org

\section{LINKED CITATIONS}

- Page 2 of 2 -

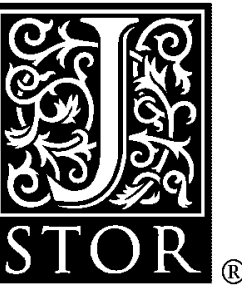

\section{Causation and Recipes}

Douglas Gasking

Mind, New Series, Vol. 64, No. 256. (Oct., 1955), pp. 479-487.

Stable URL:

http://links.jstor.org/sici?sici=0026-4423\%28195510\%292\%3A64\%3A256\%3C479\%3ACAR\%3E2.0.CO\%3B2-S

\section{Probabilistic Causation and the Pre-emption Problem}

Peter Menzies

Mind, New Series, Vol. 105, No. 417. (Jan., 1996), pp. 85-117.

Stable URL:

http://links.jstor.org/sici?sici=0026-4423\%28199601\%292\%3A105\%3A417\%3C85\%3APCATPP\%3E2.0.CO\%3B2-M

\section{Agency and Probabilistic Causality}

Huw Price

The British Journal for the Philosophy of Science, Vol. 42, No. 2. (Jun., 1991), pp. 157-176.

Stable URL:

http://links.jstor.org/sici?sici=0007-0882\%28199106\%2942\%3A2\%3C157\%3AAAPC\%3E2.0.CO\%3B2-Z

\section{Causality without Counterfactuals}

Wesley C. Salmon

Philosophy of Science, Vol. 61, No. 2. (Jun., 1994), pp. 297-312.

Stable URL:

http://links.jstor.org/sici?sici=0031-8248\%28199406\%2961\%3A2\%3C297\%3ACWC\%3E2.0.CO\%3B2-S

\section{Causality and Explanation: A Reply to Two Critiques}

Wesley C. Salmon

Philosophy of Science, Vol. 64, No. 3. (Sep., 1997), pp. 461-477.

Stable URL:

http://links.jstor.org/sici?sici=0031-8248\%28199709\%2964\%3A3\%3C461\%3ACAEART\%3E2.0.CO\%3B2-E

\section{A Causal Analysis of Seeing}

Michael Tye

Philosophy and Phenomenological Research, Vol. 42, No. 3. (Mar., 1982), pp. 311-325.

Stable URL:

http://links.jstor.org/sici?sici=0031-8205\%28198203\%2942\%3A3\%3C311\%3AACAOS\%3E2.0.CO\%3B2-T

NOTE: The reference numbering from the original has been maintained in this citation list. 